\title{
Soil porosity modelling for immersive serious game based on vertical angle, depth, and speed of tillage
}

\author{
Anang Kukuh Adisusilo a, b,1, , Mochamad Hariadi c,2, Eko Mulyanto a,3, Bambang Purwantana d,4, \\ Radi d,5 \\ ${ }^{a}$ Department of Electrical Engineering, Sepuluh November Institute of Technology, Surabaya, Indonesia \\ b Department of Informatics Engineering, University of Wijaya Kusuma, Surabaya, Indonesia \\ 'Department of Computer Engineering, Sepuluh November Institute of Technology, Surabaya, Indonesia \\ ${ }^{d}$ Departement of Agricultural and Biosystems Engineering, Universitas Gadjah Mada, Yogyakarta, Indonesia \\ ${ }^{1}$ anang65@uwks.ac.id; ${ }^{2}$ mochar@its.ac.id; ${ }^{3}$ ekomulyanto@ee.its.ac.id; ${ }^{4}$ bambang_pw@ugm.ac.id; ${ }^{5}$ radi-tep@ugm.ac.id \\ * corresponding author
}

\section{ARTICLE INFO}

\section{Article history}

Received May 28, 2018

Revised July 23, 2018

Accepted July 23, 2018

Keywords

Soil porosity

Modeling

Immersive

Serious game

Polynomial function

\section{ABSTRACT}

The real data support the "seriousness" of the serious game and give more authentic situations, which can make players feel immersed in scenarios, and gain a real experience. Therefore, the modeler must be able to recognize whether a model reflects reality to identify and deal with divergences between theory and data. In this paper, we present a model for design a basis of immersive in serious games. The studied case is the tillage using a moldboard plow, by taking real data through an experiment use a device called soil bin. It aims to determine the effect of angle, depth, and speed on the soil porosity; by comparing the value of the smallest error using the polynomial function of the use of different orders. The result of an average smallest error with the polynomial approach is $1.10 \mathrm{E}-07$ in the $3^{\text {rd }}$ order, closer to the experimental value. Therefore, the model can be used for designing immersive serious game.

This is an open access article under the CC-BY-SA license.

\section{Introduction}

Besides entertainment, the "serious games" have other purposes such as education and training. This is the reason why they are sometimes called "games with a purpose". In 1987 the Clark Act introduced the term of serious games as an effective teaching and training devices for students of all ages in many situations. Moreover, students become highly motivated because, serious games, also, offer them a rich field for a risk-free active exploration of serious intellectual and social problems [1]. Since the purpose of serious games is solving a problem, it can simulate of real-world events or processes [2]. Moreover, it can be used for transmitting contents and values attractively and efficiently [3]. In short, serious games have the purpose to increase players knowledge while playing. In this immersive situation, they do not realize that they are actually playing [4].

A modeling based on real experiments is needed to design immersivity in a serious game. The datadriven approaches show that there has been tilted towards player behavior, goal recognition, and procedural content generation [5]. The use of appropriate data modeling can be recognized as a basis for developing a serious game, make players get an in-depth experience. Several serious game research have been conducted, such as serious game designs for agricultural equipment driving training. The game is developed because the training traditionally requires high training costs, low efficiency and also high risk of accidents [6]. The research on the effects of farming machine tracks on the ground [4], model the shape form of the moldboard plow and comparing it with existing to find the optimal form of the 
plowing [7]. The model of a virtual machine farm using 3D interactive technology, dynamic web technology and database technology [8]. However, those studies have not raised the physical features of the land such as porosity as the basis for game design.

Porosity is the pore space of the soil, which is part of the land occupied by water and air; while the total pore space comprises the space among the sand, dust, and clay particles and the space between the soil aggregates [9]. The size of the void fraction in the soil material can be called porosity. The void can be connected to other parts and the outer part of the soil material is called "open", while "closed" if it is not accessible or connected to other parts including the outside of soil material [10].

The study was designed to determine mathematical models for soil porosity as an influence by vertical cutting angle, deep and speed of plowing. The soil data were taken from the soil bin experiment on the use of moldboard plow in the laboratory of Agricultural Engineering, Universitas Gadjah Mada of Yogyakarta, Indonesia. Data were analyzed by the polynomial approach using several orders, starting with order 1, 2, 3 and 4. With reference to the smallest error, the calculation of the analysis is from order 1 to order 4. These soil porosity modeling results were used as a base for the immersive serious game design. The game's serious design referred to pedagogy, play and fidelity [11], to make players gain knowledge based on their playing experience, and the freedom of interacting with the game. The impact of science can be raised on the idea of how a data-driven approach can be used to improve immersivity, so as to influence players' behavior in learning.

\section{Method}

\subsection{Proposed Method}

\subsubsection{Soil Porosity}

Soil porosity is the space between particles filled with air or water. In the pores of the soil, there are many important processes. The size of porosity, the number, and interconnection of pores are affected by the texture and structure of the soil. Because the loose arrangement of particles is larger with each other, coarse-textured soils have many pores (macropores) and soils that have smaller pores (micropores) are more finely textured soils [11]. The total porosity of fine-textured soil which has micro and macro pores is greater than all pores of coarse-textured soil. By making changes to the water and the chemical process will affect the change in porosity, while the texture will remain. Total porosity tends to decrease in the long run due to SOM reduction (soil organic matter) and large peds [12]. The entry of water into the soil will be hampered by hardened and compacted soil surfaces, thereby it reduces porosity and causes erosion. Porosity can be increased, whereas soil structure, by increasing SOM, reducing soil damage, loosening soil and minimizing erosion [10].

The total porosity $(\phi)$ is defined by the ratio of the volume of voidspace $\left(V_{V}\right)$ to the total, or bulk volume of the soil material $\left(V_{-} T\right)$ :

$$
\phi=V_{V} / V_{T}
$$

The percentage of the bulk volume of material is called porosity. Porosity functions as the transmission of nutrients from plant residues absorbed by roots as well as water that is in the pore cavity. Moreover, porosity are formed as long as plants to develop and support plant life. A low density of plant stems is between $110-120 \mathrm{~kg} \cdot \mathrm{m}^{-3}$ and $70-80 \%$ porosity (high porosity). In other words, low density, pore structure, and pore size complexity are the specific properties of bio aggregate which are able to absorb more than their own weight in water; up to four times as they produce materials with low thermal conductivity. While, Buffer values with high humidity are produced after dry shiv, so they can passively manage internal humidity levels when they are used as building materials [11].

\subsubsection{Soil Tillage}

Soil processing is a process in which the soil is engineered, to be fertilized by using a plow drawn from various sources of energy, making it suitable for planting by certain types of plants. The power for tillage sources are such as human power, animal power, and agricultural machinery. Based on the stages 
of activities, the results of work and treatment of tillage, soil processing activities are divided into two kinds, namely the primary and secondary processing. As the depth of soil processing is generally less than $15 \mathrm{~cm}$, the intensive soil erupts on the topsoil.

The process that occurs in the land plowing consists of several parts of the process, i.e. the intake process, main flow, and output. The first, the intake process is the process of separating part or soil layer from the main part. The second, main flow process is the process that occurs when the soil moves along the plow body. The last, output process is an occurred change after the ground slices apart from the tool. The characteristics of the plow are usually limited by the shape of the plow. However,they have certain characteristics; for example, the plow always has a horizontal cut point perpendicular to its direction of action.

Moldboard plow aims to break up the soil, while many types of soil suitable for the reversal of the soil and the closure of plant remains. The part of a plow is very important to produce appropriate plowing, which can be done by cutting with plowshare and removing slice groove with side control. The success of plowing is influenced by moldboard on the part of the arch, as well as the length of the moldboard which determines the degree of friability given to the ground pieces [13]. Part of the moldboard plow that cuts and flips the soil is called a bottom. A plow may consist of one bottom or more. This main parts of the bottom are moldboard, share, and landslide; which are tied to the frog part. This unit is connected to the frame through the beam rod.

As the plow moves forward, the share cuts the ground and directs the furrow slice to the moldboard. The moldboard will receive a piece of land, which because of its curvature the piece of land will be reversed and broken. This moldboard curvature is depend on soil conditions, which obtains good soil reversals and fertile [13]. The landslides serve to withstand the side pressure from the ground fissure on the moldboard and keep the stability of the road of plowing. The part that most tangents to the ground are the back called the heel. To avoid wear and tear due to friction with the ground, the manufacture of hardened is placed on the heel.

The mouldboard plow is also equipped with a tool called a cutting knife or called colter, which serves to split the soil or plants or debris that is on the ground before the plow knife cut the ground. By using the tool, the remains of plants on the ground can be reversed well and so does the work of share. There are two types of cutting knife, namely stationary knife and rolling colter knife.

\subsubsection{Immersion}

The game's purpose is to attract players to the game world in order to be consistently feel inside. It means, there is a "Suspension of Disbelief" or a mental state which players achieve during completely immersed in the game. In this situation, they do not realize that they are actually playing [14]. There are three levels that relate to the feelings of players while playing and affecting game immersive [15], namely Engagement, Engrossment, and Total Immersion.

Having access to gameplay is the initial engagement of players with the game, which is preferable. This preference can help the players easily remove the obstacles that hinder the interest of playing. For example, with an easy control even by just dabbling a game button, players will be proficient. Since the time, an investment of player involves into the game; the players will spend a lot of energy. It means, the player's effort in the game, in order to reach the target, requires great energy in playing. Therefore, to overcome the barrier, they need to be rewarded. The reward, in form of score or bonus game, is used to give the players satisfaction in playing. By breaking through obstacles earlier or having unfavorable preference access, the players will not be annoyed. Meanwhile, when the energy of player is not wasted, they will be interested in the game and want to keep playing.

Engaging in a game is heavily influenced by the design of making games, in order to make players feel drained of energy and power when they have finished. With an exciting and impressive game, players do not feel drained of energy while they are playing. Some things that are often used for planning this game are the details of the visual design of the game. In other words, the impression of luxury, task or target and plot or game plan are based on the scenario of the game story which makes the players curiously. 
The total immersive games must be able to build the players into the atmosphere of the game, resulting in experience for players in the game. The limitations of total immersive can include empathy and game atmosphere. Empathy players are usually tied to character and also the atmosphere, which is the environment of the game. The merging of various elements such as graphics, sound, and gameplay (scenarios and stories) are crucial for the formation of the total immersion. Therefore, to make a game with the total immersive; the visual, hearing and mental element of the player should to be preferred.

\subsubsection{Serious Game}

Games generally aim to please players or just give entertainment. With a fun game the players will not get bored; thus, they will have a very good fidelity. In the development, the game's purpose is not only for entertainment but also for more serious needs. Therefore, it is called serious games. A serious game is a game that is not only used for your own needs, but also for teaching media, information and education goals, by bringing the elements of experience and giving emotional freedom, which requires active users in the game.

Serious games have a purpose that players must gain knowledge from the situations while playing [16]. Thus, alike fun games, they will not get bored in serious games. The main design of serious games is pedagogy, which prioritizes the design for learning purposes, entertainment, and fidelity that prioritizes simulation design similar to reality.

Pedagogy in a serious game is an example of the instructional design which should be supported by a clear basic concept and model of how to learn and what learning is [17]. At the most basic level, it is stated that some games, such as casual games allow players to acquire the knowledge and practice skills of an interesting game environment based on behaviorist principles [18]. From the epistemological point of view, the ability can be measured from the results of learning behavior [19], where knowledge is an abstract concept. The substance of it is to play and learn from the experience which is seen as the process of each person when the transfer of information between games and players occur [20]. Player's behavior is the emphasis on practice that is closed to the actual conditions, supported by a pattern of repetition which strength the stimulus-response then changes in habits and behavior [21]. The challenges are to construct for players to feel like they are in the realm of using a data-driven approach in educational game modeling. This data-driven approach was more effective in generating contents closely matching a specific player-performance target than the heuristic-based approach [5], [22]. In contrast, many casual games give players limited choice for repetition and practice in a virtual environment based on modeling and provide a feedback for reinforcement [23]. Therefore, the theoretical approach to learn constructively rests on the epistemological assumption that the knowledge and skills constructed by learners are designed by experience [24].

The basic principle of constructivism is the importance of creating real conditions in a learning environment. From that point of view, many complex digital games such as role-playing games and multiplayer games try to create the authenticity, even allowing players to experience situations that may not be directly available. So that, through the game, an authentic and exciting environment can provide the players with various skills such as problem-solving, decision making, and social skills [25]-[28]. Moreover, it also can give advantage toward the natural motivation player-learners. That motivation can be developed in such a way as to promote intrinsic motivation, content learning, transfer of knowledge, and naturalization [29]. Function of the complex nature of the constructivism and the importance of serious game design is to assist how to learn the need for modeling based on reality. There are three things about constructivism that are commonly used to create game-based learning concepts as part of serious game design [30]. They are Situated Learning, Problem Based Learning (PBL), and Experiential Learning.

Playing in a serious game is challenging, in order to get players to take action and overcome challenges in the game. In a serious game design, the purpose is not only for entertainment, but it also provides an element of educational information. Many researchers find various ways to make this happen, as stated that the key to the serious effects of games is to balance the side of play and pedagogy [27], [31]. The 
basis of game design is that engagement, motivation, and flow are rapidly emerging in virtualization related to the immersive concept bro [15], [32].

Players often spend hours playing and repeating the same game or spend a lot of time (i.e. engagement). They spend a lot of time and energy in mastering the rules of the game and the strategy of the complicated game [14]. The power of games is to motivate, get players involved and associated with effective learning motivation which has encouraged many educators to explore the potential in learning [4], [25], [33], [34]. As advanced technologies, how to design user's involvement and how to motivate players are also developed, such as the framework by incorporating narrative, player positioning and interactive design are used as strategies in game development [35].

The concept of fidelity in the serious game refers to the extent to which the game emulates the real world [32]. There are two levels of fidelity, the first of which physically refers to the extent to which the game environment looks, sounds and feels like real. Thus, the physical fidelity of the game is determined by factors including the visual display, control, audio and variable physical model of player control [36]. The second level of fidelity is functionally defined to what extent the gaming environment acts like the real world in terms of response to the player's actions, thus encompassing game narrative elements and interactivity [32]. The rationale for fidelity in a serious game comes from dual pedagogical goal that is, (a) gain the player's interest and immersion, (b) present an effective process of learning to experience. In addition to, being supported by a realistic and $3 \mathrm{D}$ visual display, perspective of learning experience from fidelity is certain as a result in line with actual circumstances to evoke the player's experience as in the real world [30].

\subsection{Experiments Method}

The research initiates by taking data based on the speed, depth and angle of the experiment using the soil bin. The soil used is included in the sandy clay texture with the plasticity index value of $7.722 \%$, with the moisture content of about $72 \%$. The steps in the experiment use soil bin which start by calibrating its equipment, so that the to be generated data is valid. The data taken according to this research is the porosity of the soil resulting from the plowing process. Fig. 1 presents the research flow.

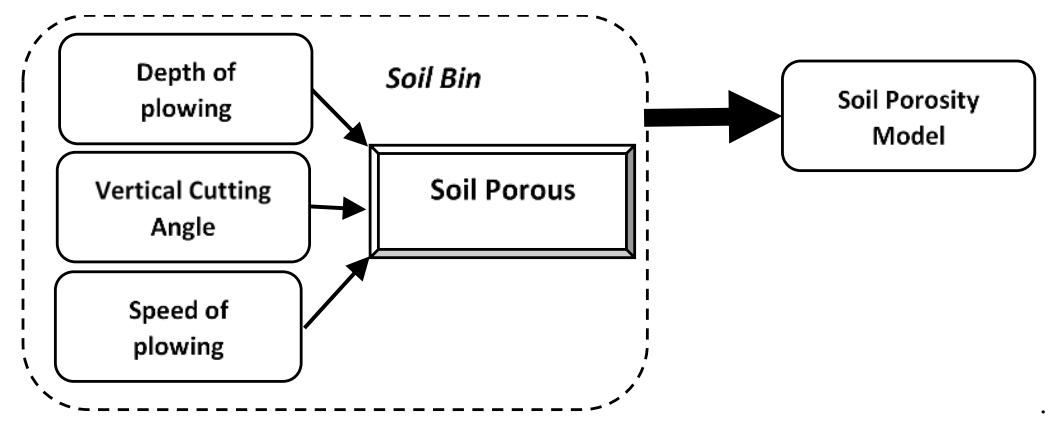

Fig. 1. Flow of the research

The part of the soil bin in Fig. 2(a), consists of 1) Soil bin tool, 2) Plowshares, 3) Box of soil, 4) Strain gauge on the beam, 5) The Wheatstone bridges, 6) Strain amplifier, 7) Microcontroller, 8) Computers and 9) Motor. The flow starts as the soil inserts into the box. In order to make soil conditions as in the field, it's necessary to have a compaction process by water for about three weeks, Fig. 2(3). By arranging the vertical cutting angle of the mouldboard plow, Fig. 2(2), the depth of plowing and the speed of the motor of Fig. 2(9), a process of ground mouldboard plow experiments is conducted. After that the force that arises from the friction plows with the soil will be measured by the strain gauge of Fig. 2(4), which is mounted on the beam. The strain gauge is an electronic component used to measure pressure (deformation or strain). Strain gauge sensors work based on changes in pressure that lead to resistance changes. In addition, to increase the sensitivity and generate the output voltage by knowing the resistor resistance of the used Wheatstone bridge, Fig. 2(5), the voltage is amplified with the Strain amplifier, Fig. 2(6), and the microcontroller Fig. 2(7). Therefore, the voltage can be directly read by a computer. 


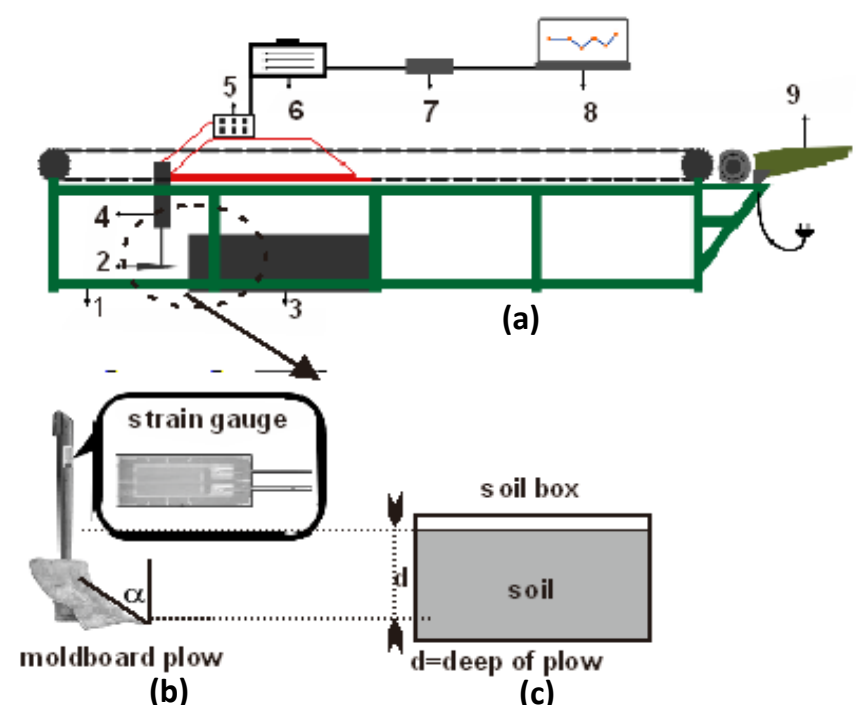

Fig. 2. Part of soil bin tools

The speed setting with the motor engine, Fig. 2(9), based on the gear is set to 3 parts, is one gear with a speed of $6.808 \mathrm{~cm} / \mathrm{s}$, two gears with a speed of $10.169 \mathrm{~cm} / \mathrm{s}$ and a three gear with a speed of 19.917 $\mathrm{cm} / \mathrm{s}$. Meanwhile, the depth of plow are two, is at $3.5 \mathrm{~cm}$ and $7 \mathrm{~cm}$. Depth setting based on soil surface on the box against the plow, Fig. 2(c), expressed in $d$ variable. Moreover, the vertical cutting angle is the angle of plow cut with three types of plows which have different vertical cutting angles, is $60^{\circ}, 65^{\circ}$ and $70^{\circ}$, as Fig. 2(b) expressed in $\alpha$ variable.

\section{Results and Discussion}

Preparation of soil by way of watering is for approximately three weeks. With three different vertical cutting angles, two depths, and three speeds; it takes 18 soil boxes of soil or 18 times running the plowing process using soil bin. The result of soil bin experiment shows in Table. 1.

Table 1. Experiment result from soil bin

\begin{tabular}{|c|c|c|c|c|c|c|}
\hline \multirow{2}{*}{$\begin{array}{c}\text { Exp } \\
\text { Number }\end{array}$} & \multirow{2}{*}{$\begin{array}{l}\text { Speed } \\
(\mathrm{cm} / \mathrm{s})\end{array}$} & \multirow{2}{*}{$\begin{array}{l}\text { Depth } \\
(\mathrm{cm})\end{array}$} & \multirow{2}{*}{$\begin{array}{l}\text { Vertical Cutting } \\
\text { angle } \\
\text { (degree) }\end{array}$} & \multicolumn{2}{|c|}{ Porosity } & \multirow{2}{*}{$\begin{array}{c}\text { Changes in } \\
\text { porosity }\end{array}$} \\
\hline & & & & $\begin{array}{l}\text { Before } \\
\text { plowing }\end{array}$ & $\begin{array}{l}\text { After } \\
\text { plowing }\end{array}$ & \\
\hline 1 & 6.808 & 3.5 & 60 & 43 & 44 & 1 \\
\hline 2 & 6.808 & 3.5 & 65 & 35 & 38 & 3 \\
\hline 3 & 6.808 & 3.5 & 70 & 41 & 45 & 4 \\
\hline 4 & 6.808 & 7 & 60 & 38 & 40 & 2 \\
\hline 5 & 6.808 & 7 & 65 & 40 & 43 & 3 \\
\hline 6 & 6.808 & 7 & 70 & 45 & 49 & 4 \\
\hline 7 & 10.169 & 3.5 & 60 & 39 & 43 & 4 \\
\hline 8 & 10.169 & 3.5 & 65 & 38 & 44 & 6 \\
\hline 9 & 10.169 & 3.5 & 70 & 40 & 47 & 7 \\
\hline 10 & 10.169 & 7 & 60 & 45 & 50 & 5 \\
\hline 11 & 10.169 & 7 & 65 & 41 & 48 & 7 \\
\hline 12 & 10.169 & 7 & 70 & 40 & 48 & 8 \\
\hline 13 & 19.917 & 3.5 & 60 & 42 & 50 & 8 \\
\hline 14 & 19.917 & 3.5 & 65 & 42 & 50 & 8 \\
\hline 15 & 19.917 & 3.5 & 70 & 40 & 50 & 10 \\
\hline 16 & 19.917 & 7 & 60 & 45 & 55 & 10 \\
\hline 17 & 19.917 & 7 & 65 & 36 & 47 & 11 \\
\hline 18 & 19.917 & 7 & 70 & 40 & 52 & 12 \\
\hline
\end{tabular}


In the Table 1, six experiments have speeds plowing is $6.808 \mathrm{~cm} / \mathrm{s}$, with a depth of plowing $3.5 \mathrm{~cm}$ in experiments one to three and a depth of plowing $7 \mathrm{~cm}$ in the experiments of four to six. The vertical angle of cutting $60^{\circ}$ is on experiment one and experiment four, while vertical angle $65^{\circ}$ on experiment two and experiment five and vertical angle $70^{\circ}$ are on experiment three and experiment six. Furthermore, at the constant of speed with different depths, it appears that there is an increase in soil porosity, where the average increase in porosity at a depth of $3.5 \mathrm{~cm}$ is 0.33 and the average increase in porosity at a depth of $7 \mathrm{~cm}$ is 0.67 . Likewise, the smaller vertical cutting angle produces soil porosity.

Using the least square approach method to determine the polynomial function $P=f(p), P$ is soil porosity and $f(p)$ is fitting function, a dependent variable $P$ from a set of independent variable in function $f(p)$ denoted,

$$
\left\{k_{1} \ldots k_{n}, l_{1} \ldots l_{n}, m_{1} \ldots m_{n}\right\}
$$

where $k$ is the speed of plowing, $l$ is vertical cutting angle and $m$ is the depth of plowing. Soil porosity equations can be generated by fitting a curve or a surface to the data points. In the case of a polynomial fit of the order $o$, these equations take the general form of,

$$
\begin{aligned}
& \tilde{k}=k+\sum_{i=0}^{n} c_{k i} k^{o^{\prime} i} k^{o^{\prime \prime} i} k^{o^{\prime \prime \prime} i} i \\
& \tilde{l}=l+\sum_{i=0}^{n} c_{l i} k^{o^{\prime} i} l^{o^{\prime \prime}}{ }^{o^{\prime \prime \prime \prime}} m^{o^{\prime}} \\
& \widetilde{m}=m+\sum_{i=0}^{n} c_{m i} k^{o^{\prime} i} l^{o^{\prime \prime} i} m^{o^{\prime \prime \prime} i} i
\end{aligned}
$$

where $c_{s i}, c_{a i}$ and $c_{d i}$ are polynomial coefficients, the value $\mathrm{n}$ depends on the order $r$ polynomial and equal to the number of permutations, where $o_{i}^{\prime}, o_{i}^{\prime \prime}$ and $o_{i}^{\prime \prime \prime}$ are the powers of the corresponding terms such that $o_{i}^{\prime}, o_{i}^{\prime \prime}, o_{i}^{\prime \prime \prime} \in\{0,1, \ldots, r\}, o_{i}^{\prime}, o_{i}^{\prime \prime}, o_{i}^{\prime \prime \prime} \leq r$ for any $i=0, \ldots, \mathrm{n}$ all permutations $\left\{o^{\prime}, o^{\prime \prime}, o^{\prime \prime \prime}\right\}$ are unique, $\tilde{k}, \tilde{l}$ and $\tilde{m}$ are a corrected values for the independent variable $k, l$ and $m$ (speed of plowing, vertical cutting angle and depth of plowing). By calculating the coefficients value, $c_{k i}, c_{l i}$ and $c_{m i}$ are used to build the fitting polynomial for each value of $k, l$ and $m$. The equations below are given for $k, l$ and $m$ have the following structure.

The equations are given for $k$ (speed of plowing) as,

$$
\left\{\begin{array}{l}
c_{k 1} k_{1}^{o_{1}^{\prime}} l_{1}^{o_{1}^{\prime \prime}} m_{1}^{o_{1}^{\prime \prime \prime}}+\cdots+c_{k i} k_{1}^{o_{1}^{\prime}} l_{1}^{o_{1}^{\prime \prime}} m_{1}^{o_{1}^{\prime \prime \prime}}+\cdots+c_{k n} k_{1}^{o_{1}^{\prime}} l_{1}^{o_{1}^{\prime \prime}} m_{1}^{o_{1}^{\prime \prime \prime}}=\bar{k}-k \\
c_{k 1} k_{j}^{o_{1}^{\prime}} k_{j}^{o_{1}^{\prime \prime}} k_{j}^{o_{1 \prime \prime}^{\prime \prime}}+\cdots+c_{k i} k_{j}^{o_{1}^{\prime}} k_{j}^{o_{1}^{\prime \prime}} k_{j}^{o_{1 \prime \prime}^{\prime \prime \prime}}+\cdots+c_{k n} k_{j}^{o_{1}^{\prime}} k_{j}^{o_{1}^{\prime \prime}} k_{j}^{o_{1}^{\prime \prime \prime}}=\bar{k}_{j}-k_{j} \\
c_{k 1} k_{q}^{o_{1}^{\prime}} l_{q}^{o_{1}^{\prime \prime}} m_{q}^{o_{1}^{\prime \prime \prime}}+\cdots+c_{k i} k_{q}^{o_{1}^{\prime}} l_{q}^{o_{1}^{\prime \prime}} m_{q}^{o_{1 \prime \prime}^{\prime \prime \prime}}+\cdots+c_{k n} k_{q}^{o_{1}^{\prime}} l_{q}^{o_{1}^{\prime \prime}} m_{q}^{o_{1}^{\prime \prime \prime}}=\bar{k}_{q}-k_{q}
\end{array}\right.
$$

The equations are given for $l$ (vertical cutting angle) as,

$$
\left\{\begin{array}{l}
c_{l 1} k_{1}^{o_{1}^{\prime}} l_{1}^{o_{1}^{\prime \prime}} m_{1}^{o_{1}^{\prime \prime \prime}}+\cdots+c_{l i} k_{1}^{o_{1}^{\prime}} l_{1}^{o_{1}^{\prime \prime}} m_{1}^{o_{1}^{\prime \prime \prime}}+\cdots+c_{l n} k_{1}^{o_{1}^{\prime}} l_{1}^{o_{1}^{\prime \prime}} m_{1}^{o_{1}^{\prime \prime \prime}}=\bar{l}-l \\
c_{l 1} k_{j}^{o_{1}^{\prime}} k_{j}^{o_{1}^{\prime \prime}} k_{j}^{o_{1}^{\prime \prime \prime}}+\cdots+c_{l i} k_{j}^{o_{1}^{\prime}} k_{j}^{o_{1}^{\prime \prime}} k_{j}^{o_{1}^{\prime \prime \prime}}+\cdots+c_{l n} k_{j}^{o_{1}^{\prime}} k_{j}^{o_{1}^{\prime \prime}} k_{j}^{o_{1}^{\prime \prime \prime}}=\bar{l}_{j}-l_{j} \\
c_{l 1} k_{q}^{o_{1}^{\prime}} l_{q}^{o_{1}^{\prime \prime}} m_{q}^{o_{1}^{\prime \prime \prime}}+\cdots+c_{l i} k_{q}^{o_{1}^{\prime}} l_{q}^{o_{1}^{\prime \prime}} m_{q}^{o_{1}^{\prime \prime \prime}}+\cdots+c_{l n} k_{q}^{o_{1}^{\prime}} l_{1}^{o_{1}^{\prime \prime}} m_{q}^{o_{1}^{\prime \prime \prime}}=\bar{l}_{q}-l_{q}
\end{array}\right.
$$

The equations are given for $m$ (depth of plowing) as,

$$
\left\{\begin{array}{l}
c_{m 1} k_{1}^{o_{1}^{\prime}} l_{1}^{o_{1}^{\prime \prime}} m_{1}^{o_{1}^{\prime \prime \prime}}+\cdots+c_{m i} k_{1}^{o_{1}^{\prime}} l_{1}^{o_{1}^{\prime \prime}} m_{1}^{o_{1}^{\prime \prime \prime}}+\cdots+c_{m n} k_{1}^{o_{1}^{\prime}} l_{1}^{o_{1}^{\prime \prime}} m_{1}^{o_{1}^{\prime \prime \prime}}=\bar{m}-m \\
c_{m 1} k_{j}^{o_{1}^{\prime}} k_{j}^{o_{1}^{\prime \prime}} k_{j}^{o_{1}^{\prime \prime \prime}}+\cdots+c_{m i} k_{j}^{o_{1}^{\prime}} k_{j}^{o_{1}^{\prime \prime}} k_{j}^{o_{o_{1 \prime \prime}}}+\cdots+c_{m n} k_{j}^{o_{1}^{\prime}} k_{j}^{o_{1}^{\prime \prime}} k_{j}^{o_{1}^{\prime \prime \prime}}=\bar{m}_{j}-m \\
c_{m 1} k_{q}^{o_{1}^{\prime}} l_{q}^{o_{1}^{\prime \prime}} m_{q}^{o_{1}^{\prime \prime \prime}}+\cdots+c_{m i} k_{q}^{o_{1}^{\prime}} l_{q}^{o_{1}^{\prime \prime}} m_{q}^{o_{1}^{\prime \prime \prime}}+\cdots+c_{m n} k_{q}^{o_{1}^{\prime}} l_{q}^{o_{1}^{\prime \prime}} m_{q}^{o_{1}^{\prime \prime \prime}}=\bar{m}_{q}-m_{q}
\end{array}\right.
$$

that can be written in the matrix for $\boldsymbol{k}=\boldsymbol{K} \boldsymbol{t}, \boldsymbol{l}=\boldsymbol{L u}$ and $\boldsymbol{m}=\boldsymbol{M v}$ as,

The matrix from $\boldsymbol{k}=\boldsymbol{K} \boldsymbol{t}$, as, 


$$
\boldsymbol{K}=\left[\begin{array}{ccccc}
k_{1,1} & \cdots & k_{1, i} & \cdots & k_{1, n} \\
\vdots & \ddots & \vdots & \ddots & \vdots \\
k_{j, 1} & \cdots & k_{j, i} & \cdots & k_{j, n} \\
\vdots & \cdots & \vdots & \cdots & \vdots \\
k_{q, 1} & \cdots & k_{q, i} & \cdots & k_{q, n}
\end{array}\right] \boldsymbol{t}=\left[\begin{array}{c}
t_{1} \\
\cdots \\
t_{j} \\
\cdots \\
t_{n}
\end{array}\right] \boldsymbol{k}=\left[\begin{array}{c}
k_{1} \\
\cdots \\
k_{j} \\
\cdots \\
k_{n}
\end{array}\right]
$$

The matrix from $\boldsymbol{l}=\boldsymbol{L} \boldsymbol{u}$, as,

$$
\boldsymbol{L}=\left[\begin{array}{ccccc}
l_{1,1} & \cdots & l_{1, i} & \cdots & l_{1, n} \\
\vdots & \ddots & \vdots & \ddots & \vdots \\
l_{j, 1} & \cdots & l_{j, i} & \cdots & l_{j, n} \\
\vdots & \cdots & \vdots & \cdots & \vdots \\
l_{q, 1} & \cdots & l_{q, i} & \cdots & l_{q, n}
\end{array}\right] \boldsymbol{u}=\left[\begin{array}{c}
u_{1} \\
\cdots \\
u_{j} \\
\cdots \\
u_{n}
\end{array}\right] \boldsymbol{l}=\left[\begin{array}{c}
l_{1} \\
\cdots \\
l_{j} \\
\cdots \\
l_{n}
\end{array}\right]
$$

The matrix from $\boldsymbol{m}=\boldsymbol{M} \boldsymbol{v}$, as,

$$
\boldsymbol{M}=\left[\begin{array}{ccccc}
m_{1,1} & \cdots & m_{1, i} & \cdots & m_{1, n} \\
\vdots & \ddots & \vdots & \ddots & \vdots \\
m_{j, 1} & \cdots & m_{j, i} & \cdots & m_{j, n} \\
\vdots & \cdots & \vdots & \cdots & \vdots \\
m_{q, 1} & \cdots & m_{q, i} & \cdots & m_{q, n}
\end{array}\right] \boldsymbol{v}=\left[\begin{array}{c}
v_{1} \\
\cdots \\
v_{j} \\
\cdots \\
v_{n}
\end{array}\right] \boldsymbol{m}=\left[\begin{array}{c}
m_{1} \\
\cdots \\
m_{j} \\
\cdots \\
m_{n}
\end{array}\right]
$$

where $\left(k_{j, i}=k_{j}^{o_{i}^{\prime}} l_{j}^{o_{i}^{\prime \prime}} m_{j}^{o_{i}^{\prime \prime \prime}}, l_{j, i}=k_{j}^{o_{i}^{\prime}} l_{j}^{o_{i}^{\prime \prime}} m_{j}^{o_{i}^{\prime \prime \prime}}, m_{j, i}=k_{j}^{o_{i}^{\prime}} l_{j}^{o_{i}^{\prime \prime}} m_{j}^{o_{i}^{\prime \prime \prime}}\right), \quad\left(t_{i}=c_{k, i}, u_{i}=c_{l, i}, v_{i}=\right.$ $\left.c_{m, i}\right)$ and $\left(k_{j}=\bar{k}-k, l_{j}=\bar{l}-l, m_{j}=\bar{m}-m\right)$, the predicted values of the dependent varible $\tilde{s}$ are collected in vector denoted $\widehat{\boldsymbol{k}}, \hat{\boldsymbol{l}}$ and $\widehat{\boldsymbol{m}}$ and are obtained as:

$$
\begin{aligned}
& \boldsymbol{k}=\boldsymbol{K} \boldsymbol{t} \text { with } \boldsymbol{t}=\left(\boldsymbol{K}^{T} \boldsymbol{K}\right)^{-1} \boldsymbol{K} \boldsymbol{k} \\
& \boldsymbol{l}=\boldsymbol{L} \boldsymbol{u} \text { with } \boldsymbol{u}=\left(\boldsymbol{L}^{T} L\right)^{-1} \boldsymbol{L} \boldsymbol{} \\
& \boldsymbol{m}=\boldsymbol{M} \boldsymbol{v} \text { with } \boldsymbol{v}=\left(\boldsymbol{M}^{T} M\right)^{-1} M m
\end{aligned}
$$

From the raw data in Table 1, using the general equation of polynomial from Equation (3), we can be defined variable $\tilde{k}$ for the speed of plowing as,

$$
\tilde{k}=k+\left(c_{k 1} k_{1}^{o_{0}^{\prime}} l_{1}^{o_{0}^{\prime \prime}} m_{1}^{o_{0}^{\prime \prime \prime}}+\cdots+c_{k i} k_{j}^{o_{i}^{\prime}} l_{j}^{o_{i}^{\prime \prime}} m_{j}^{o_{i}^{\prime \prime \prime}}+\cdots+c_{k n} k_{q}^{o_{n}^{\prime}} l_{q}^{o_{n}^{\prime \prime}} m_{q}^{o_{n}^{\prime \prime \prime}}\right)
$$

by comparing the value of the smallest error, is generated in the $3^{\text {rd }}$ order with an error $2,13528659445375 \mathrm{e}-08$, so the value $c_{k, i}$ is constant value $, i=\{0,1, \ldots, n\}, n=3$ and $j=$ $\{1,2, \ldots, q\}, q=64$. With the value of speed is constant $6.8085 \mathrm{~cm} / \mathrm{s}$ in order 3 from equation (15), graphic in Fig. 3.

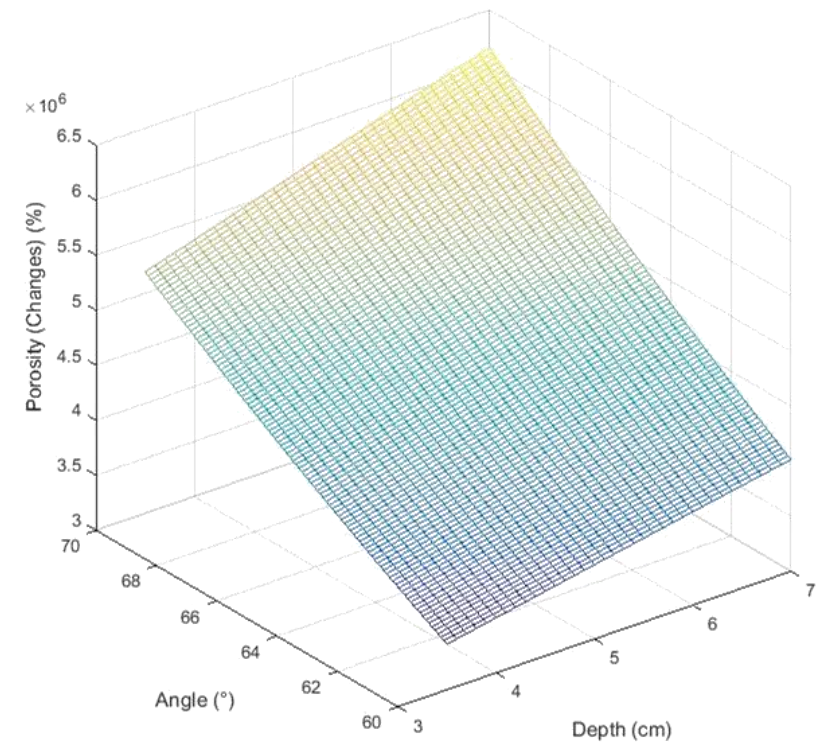

Fig. 3. Graphic of relationship for vertical angle and depth to soil porosity with constant speed of plowing in $3^{\text {rd }}$ order 
The equations for two other variables can be built in the same way using $\tilde{l}$ and $\widetilde{m}$ as the following:

$$
\begin{aligned}
& \tilde{l}=l+\left(c_{l 1} k_{1}^{o_{0}^{\prime}} l_{1}^{o_{0}^{\prime \prime}} m_{1}^{o_{0}^{\prime \prime \prime}}+\cdots+c_{l i} k_{j}^{o_{i}^{\prime}} l_{j}^{o_{i}^{\prime \prime}} m_{j}^{o_{i}^{\prime \prime \prime}}+\cdots+c_{m n} k_{q}^{o_{n}^{\prime}} l_{q}^{o_{n}^{o^{\prime \prime}}} m_{q}^{o_{n}^{\prime \prime \prime}}\right) \\
& \widetilde{m}=m+\left(c_{m 1} k_{1}^{o_{0}^{\prime}} l_{1}^{o_{0}^{\prime \prime}} m_{1}^{o_{0}^{\prime \prime \prime}}+\cdots+c_{m i} k_{j}^{o_{i}^{\prime}} l_{j}^{o_{i}^{\prime \prime}} m_{j}^{o_{i}^{\prime \prime \prime}}+\cdots+c_{m n} k_{q}^{o_{n}^{\prime}} l_{q}^{o_{n}^{\prime \prime}} m_{q}^{o_{n}^{\prime \prime \prime}}\right)
\end{aligned}
$$

The value of the smallest error from equation (16) in the polynomial is $2,88166918080732 \mathrm{e}-07$ in the $3^{\text {rd }}$ order. With the value of vertical cutting angle is constant $60^{\circ}$ can be generated graphics in Fig. 4. Where $c_{l, i}$ is constant value, $i=\{0,1, \ldots, n\}, n=3$ and $j=\{1,2, \ldots, q\}, q=64$.

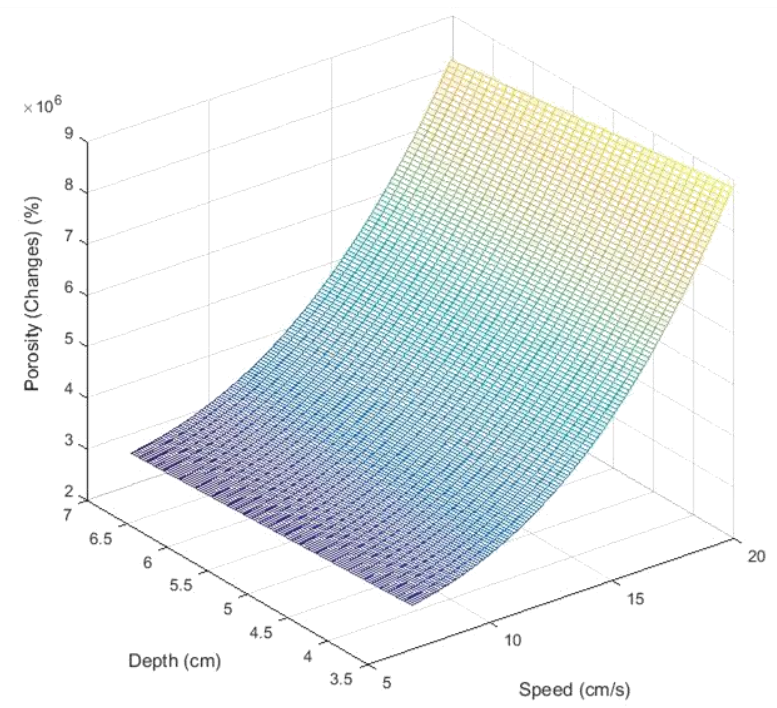

Fig. 4. Graphic of relationship for speed of plowing and depth to soil porosity with constant vertical cutting angle of plowing in $3^{\text {rd }}$ order

Graphics in Fig. 5 is produced from equation (17) in order 3 with a constant depth of $3.5 \mathrm{~cm}$ and the result the polynomial error is $2.13528659445375 \mathrm{e}-08$. Where $c_{m, i}$ is constant value, $i=$ $\{0,1, \ldots, n\}, n=3$ and $j=\{1,2, \ldots, q\}, q=64$.

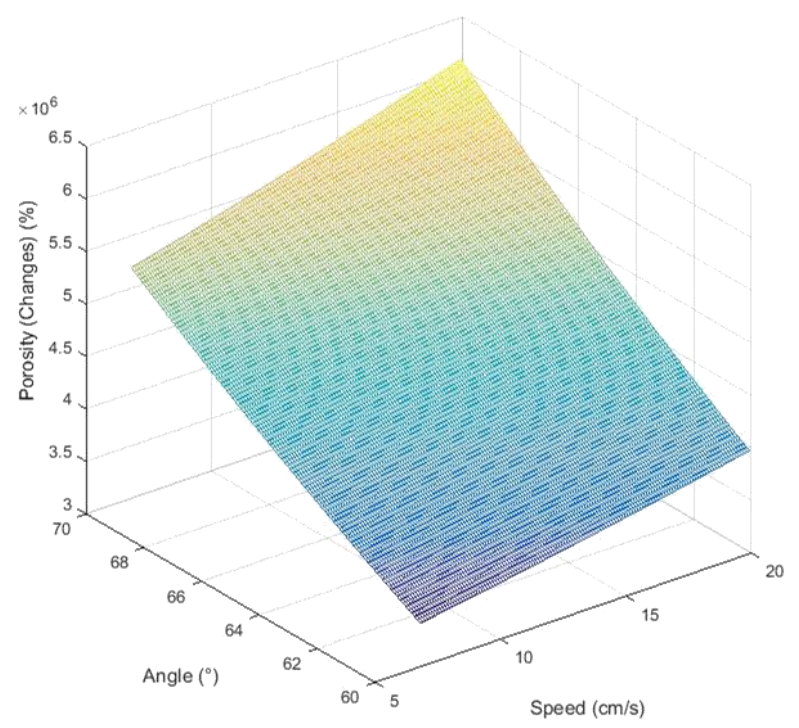

Fig. 5. Graphic of relationship for vertical cutting angle and speed to soil porosity with constant depth of plowing in $3^{\text {rd }}$ order

A small error value indicates that the resulting model is close to the actual data. Furthermore, there is a similarity in the $3^{\text {rd }}$ order and the smallest error which is generated. While, from the graphic, it 
indicates that as the larger the vertical cutting angle, the deeper and the faster porosity changes. In short, the porosity model $P$ is as follow

$$
P=\{\tilde{k}, \tilde{l}, \widetilde{m}\}
$$

where all variables are fitted by the $3^{\text {rd }}$ order polynomial.

The result of soil bin experiment is a set of training and model representation in equations (15), (16) and (17) is called learning algorithm which can be used as the hypothesis of porosity value, if hypothesis using linear regression $h$, as shown in Fig. 6.

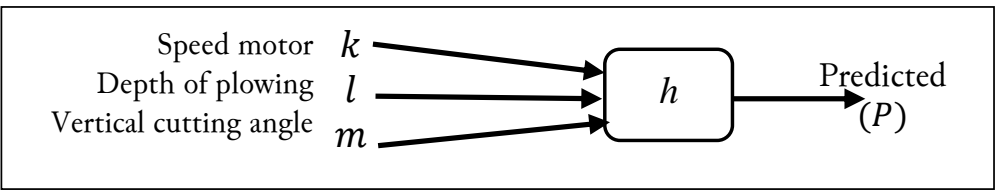

Fig. 6. Diagram for hypothesis of porosity

The graph for experimental comparison with the hypothesis shows that it has similarities, with error 7.54656310281771e-09 (Fig. 7). It shows the model is close to the actual value.

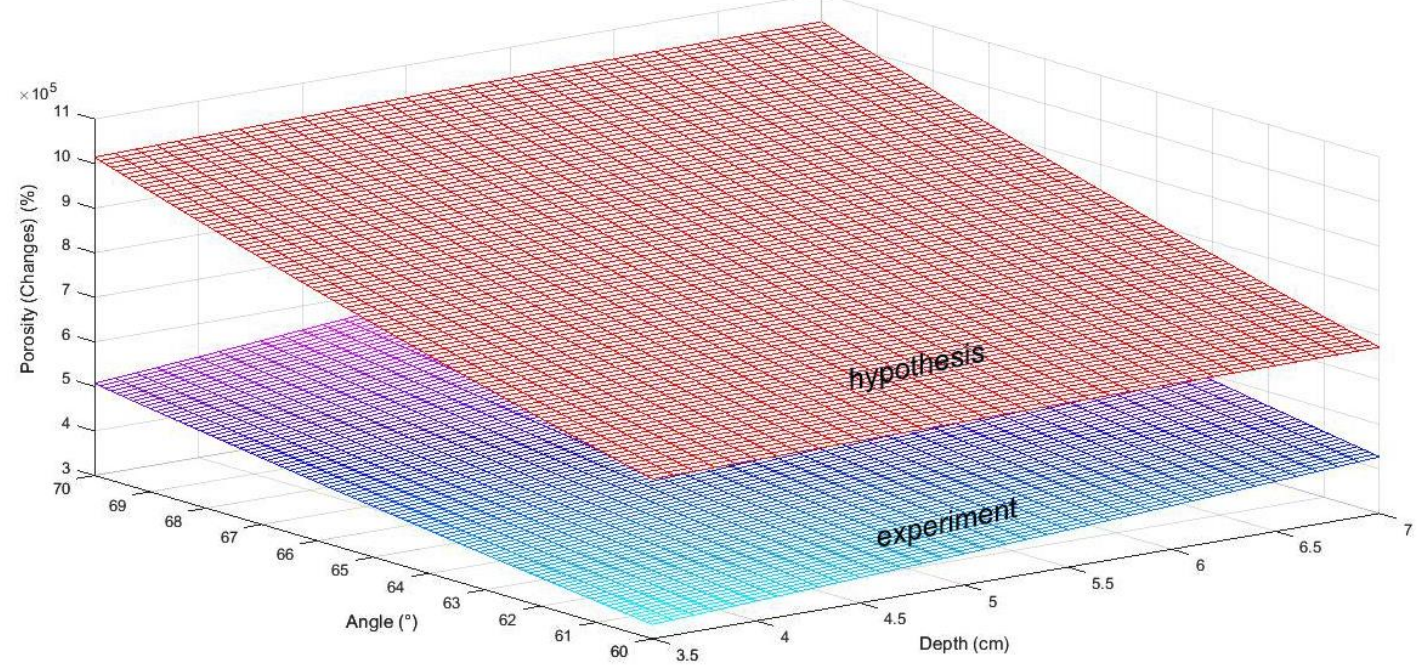

Fig. 7. Experimental comparison with the hypothesis.

The preliminary implementation of the immersive serious game design is based on the soil porosity model using HSM (Hierarchical finite state machines), where the polynomial function $P=f(p)$ becomes a state, in Fig. 8 .

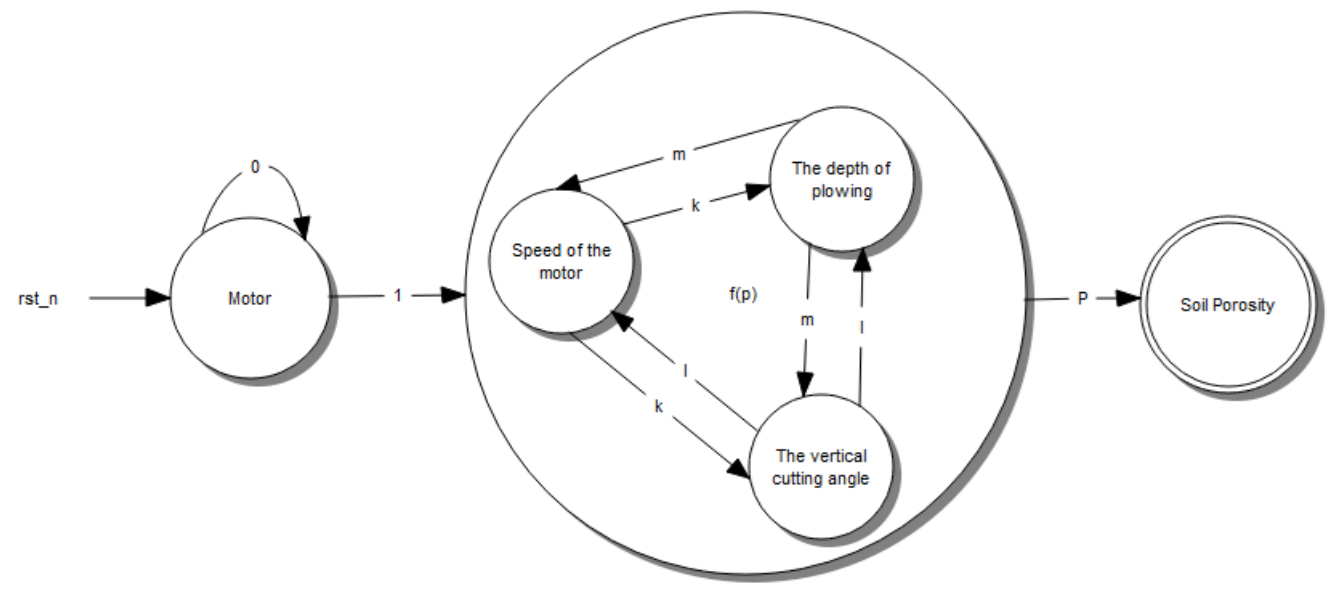

Fig. 8. Design serious game using HFSM (Hierarchical Finite State Machines) 
Starting with the motor initial state, when there is a transition value of 1 , the motor starts to move; however, the motor stops if it is 0 . Superstate $f(p)$ is a polynomial function influenced by transition $k$ for substate speed of the motor, transition $l$ for substate the vertical cutting angle, and transition $m$ for substate the depth of plow. From these parameters, they relate each other and produce the transition value $\mathrm{P}$ which is state of the soil porosity.

The Simple implementation for calculations is done by assigning values to the speed of plowing, vertical cutting angle and the depth of plowing $(k, l, m)$. For example,the value for the speed of plowing, vertical cutting angle and the depth $(6,8083,560)$, using the polynomial 3rd order formula is generated soil porosity 43.9650304907293 . The value is almost equal to the porosity value in the experiments that have been done, showing in Table. 1. The parameters are the transition of substate speed of the motor $\mathrm{k}=6.808$, the transition of substate the vertical cutting angle $\mathrm{l}=3.5$ and the transition substate the depth of plow $\mathrm{m}=60$. These parameters are relate each other and produce the transition value $P$ $=43.9650304907293$ which is state of the soil porosity.

\section{Conclusion}

The modeling shows that the greater value of Vertical Angle, Depth, and Speed of Tillage may increase the soil porosity. The learning algorithm produce a hypothesis that has similarities with the experimental results. In other words, the model can be used as the basis for designing the serious game. Immersive environment caused the simulation closer to the actual data. The best-individualized learning may generate intrinsic motivation, can create a better state of immersive serious game.

\section{References}

[1] C. C. Abt, Serious games. University Press of America, 1987, available at: books.google.com.

[2] B. Sawyer, Improving public policy through game-based learning and simulation,foresight and governance project: Woodrow Wilson International Center for Scholars, 1st ed. Digitalmill, Inc, 2002, available at: https://docslide.net/documents/serious-games-improving-public-policy-through-gamebased-learningand-simulation.html.

[3] P.-M. Noemí and S. H. Máximo, "Educational Games for Learning," Univers. J. Educ. Res., vol. 2, no. 3, pp. 230-238, 2014, doi: https://doi.org/10.13189/ujer.2014.020305.

[4] A. Alexander, T. Brunyé, J. Sidman, and S. a Weil, "From gaming to training: A review of studies on fidelity, immersion, presence, and buy-in and their effects on transfer in pc-based simulations and games," DARWARS Train. Impact Gr., no. November, p. 14, 2005, doi: https://doi.org/10.1016/j.athoracsur. 2004.02.012.

[5] D. Hooshyar, M. Yousefi, and H. Lim, "Data-Driven Approaches to Game Player Modeling," ACM Comput. Surv., vol. 50, no. 6, pp. 1-19, Jan. 2018, doi: https://doi.org/10.1145/3145814.

[6] Q. Ma, Z. Yang, H. Chen, D. Zhu, and H. Guo, "A Serious Game for Teaching and Learning Agricultural Machinery Driving," 2012 Int. Conf. Artif. Intell. Soft Comput., vol. 12, pp. 56-62, 2012, available at: http://cstm.cnki.net/stmt/TitleBrowse/KnowledgeNet/XXGC201203002012?db=STMI8515.

[7] H.S. Jeshvaghani, S.K.H. Dehkordi, M.F. Samani, and H.R. Dehkordi, "Comparison and Optimization of Graphical Methods of Moldboard Plough Bottom Design Using Computational Simulation," J. Am. Sci., no. 6, pp. 414-420, 2013, available at: http://www.jofamericanscience.org/journals/am-sci/am0906/ 050_7273am0906_414_420.pdf.

[8] L. Jianjun, "The Study on Agricultural Machinery Design and Modeling Method," Int. J. Adv. Comput. Technol. , vol. 4, no. 22, pp. 678-684, 2012, doi: https://doi.org/10.4156/ijact.vol4.issue22.78.

[9] G. Soepardi, Sifat dan ciri tanah (Soil properties and characteristic). Indonesia: Bogor Agricultural University, 1983, available at: https://books.google.co.id.

[10] A. McCauley, C. Jones, and J. Jacobsen, "Basic Soil Properties," Soil Water, pp. 1-12, 2005, available at: http://johnmischler.com/AgroReadings/Soil_physical_props.pdf. 
[11] E. Latif, M. Lawrence, A. Shea, and P. Walker, "Moisture buffer potential of experimental wall assemblies incorporating formulated hemp-lime," Build. Environ., vol. 93, no. P2, pp. 199-209, 2015, doi: https://doi.org/10.1016/j.buildenv.2015.07.011.

[12] N. C. Brady and R. R. Weil, The nature and properties of soils, no. Ed. 14. 2014, available at: https://www.pearson.com/us/higher-education/product/Brady-Nature-and-Properties-of-Soils-The-14thEdition/9780132279383.html.

[13] H. P. Smith and L. H. Wilkes, Farm machinery and equipment. McGraw-Hill translate by Tri Purwadi ; editor: GembongTjitro-soepomo, (1990), Yogyakarta : GadjahMada University Press, 1976, available at: http://library.um.ac.id.

[14] R. Rouse, Game Design: Theory \& Practice, USA: Wordware Publishing Inc, 2000, available at: https://dl.acm.org/citation.cfm?id=582921.

[15] E. Brown and P. Cairns, "A grounded investigation of game immersion," in Extended abstracts of the 2004 conference on Human factors and computing systems - CHI '04, 2004, p. 1297, doi: https://doi.org/ 10.1145/985921.986048.

[16] A. F. S. Barbosa, P. N. M. Pereira, J. A. F. F. Dias, and F. G. M. Silva, "A New Methodology of Design and Development of Serious Games," Int. J. Comput. Games Technol., vol. 2014, pp. 1-8, 2014, doi: https://doi.org/10.1155/2014/817167.

[17] P. Zemliansky and D. M. Wilcox, Design and implementation of educational games: theoretical and practical perspectives. Information Science Reference, 2010, available at: https://books.google.com.

[18] M. Kebritchi and A. Hirumi, "Examining the pedagogical foundations of modern educational computer games," Comput. Educ., vol. 51, no. 4, pp. 1729-1743, 2008, doi: https://doi.org/10.1016/j.compedu. 2008.05.004.

[19] P. Jarvis, J. Holford, and C. Griffin, The theory and practice of learning. Kogan Page, 2003, available at: https://books.google.co.id.

[20] B. D. Ruben, "Simulations, games, and experience-based learning: The quest for a new paradigm for teaching and learning," Simul. Gaming, vol. 30, no. 4, pp. 498-505, 1999, doi: https://doi.org/10.1177/104687819903000409.

[21] J. E. Ormrod, Human Learning. 2012, available at: https://fjjm9kvbg02.storage.googleapis.com/MDEz MzU3OTI4WA==02.pdf.

[22] D. Hooshyar, M. Yousefi, and H. Lim, "A systematic review of data-driven approaches in player modeling of educational games," 2017, pp. 1-21, doi: https://doi.org/10.1007/s10462-017-9609-8.

[23] M. J. Mayo, "Video games: A route to large-scale STEM education?," 2009, vol. 323, no. 5910, pp. 79-82, doi: https://doi.org/10.1126/science.1166900.

[24] M. P. Driscoll, "Psychology of learning for instruction," Learn. Instr., vol. 3rd, p. xvi, 448, 2005, doi: https://doi.org/10.1007/BF02504860.

[25] R. Van Eck, “Building Artificially Intelligent Learning Games," 2007, pp. 271-307, doi: https://doi.org/ 10.4018/978-1-59904-304-3.ch014.

[26] D. G. Oblinger, “The Next Generation of Educational Engagement," J. Interact. Media Educ., vol. 2004, no. 8, pp. 1-18, 2004, doi: https://doi.org/10.5334/2004-8-oblinger.

[27] S. De Freitas, "Learning in Immersive worlds A review of game-based learning Prepared for the JISC eLearning Programme," JISC eLearning Innov., vol. 3.3, no. October 14, p. 73, 2006, doi: https://doi.org/ 10.1111/j.1467-8535.2009.01024.x.

[28] A. B. Meijer and H. Koppelaar, "Towards Multi-Objective Game Theory - With Application To Go," in GAME-ON, 2003, p. 243, availbale at: http://www.mmi.tudelft.nl/pub/alex/meijer-gameon03.pdf.

[29] R. F. Kenny and G.A. Gunter, "Endogenous Fantasy - Based Serious Games: Intrinsic Motivation and Learning," Int. J. Soc. Sci., vol. 2, no. 1, pp. 8-13, 2007, available at: http://citeseerx.ist.psu.edu/viewdoc/ download?doi=10.1.1.135.1365\&rep=rep1\&type=pdf. 
[30] P. Rooney, "A theoretical framework for serious game design: Exploring pedagogy, play and fidelity and their implications for the design process," Int. J. Game-Based Learn., vol. 2, no. 4, pp. 41-60, 2012, doi: https://doi.org/10.4018/ijgbl.2012100103.

[31] M. Seeney and H. Routledge, "Drawing circles in the sand: Integrating content into serious games," 2009, pp. 84-97, doi: https://doi.org/10.4018/978-1-60566-360-9.ch006.

[32] M. McMahon and C. Ojeda, "A Model of Immersion to Guide the Design of Serious Games," World Conf. ELearning Corp. Gov. Healthc. High. Educ. 2008, p. 1833-1842 ST-A Model of Immersion to Guide the, 2007, available at: https:/www.learntechlib.org/p/29908/.

[33] M. Prensky, "Digital game-based learning," Comput. Entertain., vol. 1, no. 1, p. 21, 2003, doi: https://doi.org/10.1145/950566.950596.

[34] K. Kiili, "Digital game-based learning: Towards an experiential gaming model," Internet High. Educ., vol. 8, no. 1, pp. 13-24, 2005, doi: https://doi.org/10.1016/j.iheduc.2004.12.001.

[35] B. A. Whitton, N. T. W. Ellwood, and B. Kawecka, "Biology of the freshwater diatom Didymosphenia: a review," Hydrobiologia, vol. 630, no. 1, pp. 1-37, Sep. 2009, doi: https://doi.org/10.1007/s10750-009-97535.

[36] M. D. Dickey, "Engaging by design: How engagement strategies in popular computer and video games can inform instructional design,” Educ. Technol. Res. Dev., vol. 53, no. 2, pp. 67-83, 2005, doi: https://doi.org/10.1007/BF02504866. 